\title{
Editorial
}

It is a pleasure to introduce this year's special issue, "Black/African Transatlantic Voices in Mission Studies." As a Journal, we publish both historical articles and those responding in a timely way to current events. When we received a submission in 2019 engaging the dearth of African American voices in the field of mission studies, we could not have anticipated that by the time of its publication in June 202O, the world would be reeling from the filmed murder of George Floyd on 25 May 2020, just a few weeks earlier (see Dwight A. Radcliff, Jr., "Black-ish Missiology: A Critique of Mission Studies and Appeal for Inclusion in the United States Context," 37:2).

Responses to the painful realities of contemporary and historic anti-Black racism and myriad forms of discrimination reverberated around the transatlantic world, while many faith communities sought to explore meaningful avenues for engagement, activism, and reconciliation. The providential timing of Radcliff's article caught our attention, and in reflecting on his call for the inclusion of more African American voices within mission studies (both the field and the Journal), we felt that a wider, transatlantic response was important. We therefore invited Dwight Radcliff, Jr. (USA), together with Daniel Justice Eshun (UK) and Damaris Parsitau (KENYA), to guest edit this special issue.

Our hope, and theirs, is to highlight historic and contemporary Black and African voices that are often marginalized within missiological discourse, foregrounding different perspectives and experiences within world missions. These guest editors have worked tirelessly to bring this special issue together within a short timeframe in order to capture the zeitgeist of this moment in a fresh way. It has been a pleasure to collaborate with them, and we sincerely thank them for all of their hard work. Thanks also go to peer reviewers and other colleagues who graciously went above and beyond in providing detailed feedback and editorial input as their way of supporting this endeavour. Their efforts have added much value to this issue. And as always, our thanks go to the authors and book reviewers who have worked diligently, while often facing significant challenges in what has been an exceptionally difficult year on many fronts.

In the midst of an already heavy season, we have also recently lost several pioneering colleagues, whose obituaries are included here. While every loss is difficult, the deaths of both Andrew. F. Walls (93) and Wilbert R. Shenk (86) this past summer represent a particularly heavy blow for missiology and World 
Christianity. It is the end of an era. In reading their obituaries, we invite readers to pause and reflect upon the legacies of these "founding ancestors," who have served so many of us as colleagues, lecturers, supervisors, mentors, and friends. An Akan proverb says, "the child sees further because the father carries her on his shoulders." May their immense scholarly contributions, as well as their examples of humility and goodwill, enable us to "see further" as we gratefully continue to build upon the foundations they have laid.

Finally, it is a pleasure to announce that this issue has generously been sponsored for Open Access publication. This includes Radcliff's 2020 article, to which we invite readers to return and read as the catalyst for this special issue. As you move through these pages, it is sobering to bear witness, on the one hand, to injustice, violence, and trauma; but on the other, hopeful to be reminded that resurrection has the final word.

\section{Sara Fretheim}

Assistant Editor

imw@uni-muenster.de 